\section{Iceland out in the cold}

SIR - Having enjoyed British postgraduate medical and scientific training and collaboration from 1968 to 1981 , I read with interest your survey on Nordic Science (Nature 360, 511-529; 1993).

To my surprise and disappointment, Iceland, traditionally regarded as a member of the Nordic group of nations, was excluded without explanation. While understanding the necessity of being selective in such a survey, I cannot quite appreciate such dismissal of my mother country, the smallest in terms of population but one that has the world's longest democratic tradition.

Although there is room for much improvement in Iceland as regards funding and political understanding of the importance of scientific research as an essential ingredient of our livelihood and survival as an independent people, it does not justify your ignoring completely in this context significant scientific contributions by a well educated people.

My anger got dispersed by the comforts of Christmas but the issue of 21 January (Nature 361, 194; 1993), brought an apology that made me reach for my pen. Your survey showed two maps, a satellite view across Scandinavia on the cover, and a map of Scandinavia, Denmark and Finland together with adjacent continental European countries on page 510 . On both, Iceland, usually an undoubted member of the Nordic countries, is not shown. Surprisingly though, when Nature does see reason for correction, it is to apologize for the omission of Poland from the map!

The days of great geographical explorations are over. Instead we are now faced with exploring the world of possibilities offered by natural resources and the ingenuity of our minds. Scientific ideas and communications are not and should not be limited by manmade boundaries. But as we are "heading into an uncertain future", preservation of and respect for cultural diversity may ensure fertility of ideas and a nation's size may be irrelevant to the importance of its contribution in this respect.

Gudrún Agnarsdóttir

Institute for Experimental Pathology,

University of Iceland, Keldur

IS-112 Reykjavik

Iceland

\section{Consent laws}

SIR - I refer to the article (Nature 361, 102 ; 1992) by Declan Butler concerning the work on French children born by artificial insemination by donor (AID).
He states the issues succinctly by quoting the views of Claude Paoletti, director of life sciences at the CNRS, and Jean Bernard, the former president of the (French) national bioethics advisory committee, to the effect that present laws put researchers in a dilemma. I hope that scientists in the European Communities will take cognizance of these views in framing the ethics for research on human populations.

Regrettably, I was in India when Butler visited our laboratory, so did not have the opportunity to discuss this study (of which I am the first author). The description given to Butler of some aspects needs to be clarified. Given the controversy in French newspapers relating to our research it is absolutely necessary that facts in a scientific journal be correct.

It may help researchers to understand the possibilities and limitations of our work if I state clearly its purposes. The quality of data on the cognitive traits of children is variable. Questions relating to the data of Sir Cyril Burt have not helped matters. I and my colleagues wish to provide the scientific community with reliable data on cognitive traits of related children. Given reliable data, the understanding of cognitive and genetic processes may be a little easier. Both the choice of the cognitive trait and the method are important. A trait that is not stable in the population under study is not a suitable object for psychometric or genetic analysis. The relevance of the half-sib method for complex traits is well established in quantitative genetics. It has not been used for the study of cognitive traits because of the difficulty of finding half-sib samples and, when they are found, some environmental factors are invariably involved. To avoid confounding these factors, we decided to study children born by AID

Our study was in two stages: (1) to find which of the available tests would be appropriate for use on French children by using sibs as well as unrelated children and (2) to extend our previous study of cognitive traits on sibs to halfsibs by using the tests selected for their reliability and appropriateness for analysis.

In the current 'half-sib' study, our tested sample consisted of about 3,100 children aged between 7.5 and 14 years, of which 103 are half-sibs produced by AID and 103 were in the control group. Clearly, with these samples, there was no way we could assess "pre- and postnatal effects of artificial insemination .... on the children of the same father". The research is not yet complete. After its completion, if the statistical analysis shows differences between the children born by AID and the control group, we shall then look into the causes of the differences (see, with respect to adoption ref. 1).

With our design, it is not possible for us to "test whether assisted procreation itself could cause harmful neurological or psychological effects". The half-sib method gives us the opportunity to estimate the additive effect of genes causing the resemblance among the half-sibs of the same donor reared in different environments in probabilistic terms. The estimate of genetic parameters is less inflated. As the design uses paternal half-sibs, it not only eliminates a nonadditive genetic effect - for example, dominance effect due to interaction between allelic forms of one gene at the same locus - but also DNA mitochondrial maternal effects. In addition, some environmental effects causing resemblance are eliminated. This enables us to estimate the effects of common environment on half-sib groups. As this is the first study of its type, we hope that it will provide a sound empirical and theoretical basis for research in cognitive traits. I must, however, emphasize that, given the design of the project, only limited inferences can be made from it.

Butler notes that the author of the report in L'Express acknowledges "that his perspective is coloured by his vociferous opposition to the genetic bases of human behaviour". The excesses of some behavioural geneticists are well known. I have myself drawn the attention of the scientific community to the weaknesses of their research ${ }^{2-5}$. Using poor data, on the basis of the model fitting they make exaggerated claims. Our study provides data not only on 103 children born by AID but also on certain traits of more than 3,000 other French children. Some researchers may regard the availability of reliable data on these children as a contribution to scientific knowledge.

The ethical problems posed involve the philosophical values of the scientific community as well as those of the community at large. These need to be discussed and debated, but in an informed way. The scientific content of research must remain in the domain of scientists but the community has the right and indeed the duty to set the parameters in which this research takes place.

\section{Christiane Capron}

Paris X-Nanterre,

CNRS URA 1294 Université Paris V France

1. Duyme, M. Les enfants abandonnés, Monograph No. 56 CNRS. (1981)

2. Duyme, M. \& Capron, C. Behav. Brain Sci. 14, 393 (1990)

3. Roubertoux, P. L. \& Capron, C. Eur. Bull. cogn Psychol. 10. $555-594$ (1990).

4. Capron, C. \& Duyme, C. Eur. Bull. cogn Psychot. 11 , 323-348 (1991).

Duyme, M. \& Capron, C. Eur. Bull. cogn Psychol. 12 585-604 (1992). 